\title{
Therapeutic metformin/AMPK activation promotes the angiogenic phenotype in the ER $\alpha$ negative MDA-MB-435 breast cancer model
}

\author{
Sirwan M. Hadad · Virginia Appleyard • \\ Alastair M. Thompson
}

Received: 7 April 2008/Accepted: 8 April 2008/Published online: 18 April 2008

(C) Springer Science+Business Media, LLC. 2008

MDA-MB-435 cell line has been used for decades as a model of metastatic human breast cancer [1]. This cell line was derived at M.D. Anderson in 1976 from a pleural effusion from a 31-year old woman with a history of breast cancer [2,3]. However, recent advances in gene expression analysis, which allow the opportunity to more fully characterize tumour cell lines, revealed that the pattern of gene expression for MDA-MB-435 is more closely resembles melanoma cell lines than breast tumour lines [4]. These findings prompted Ellison et al. to undertake a more detailed study of the characteristics of MDA-MB-435 [5]. In brief, they confirmed that breast-specific genes were not detectably expressed in MDA-MB-435 compared to most of the breast tumour cell lines they were investigating. Furthermore, melanocyte-specific genes were expressed in MDAMB-435, as well as in most of the other melanoma cell lines, but were not detectable in the other breast tumour cell lines. Additionally, xenografts of MDA-MB-435 implanted into mammary fat pads of female Severe Combined Immunodeficiency (SCID) mice showed immunohistochemical staining consistent with melanocytic origin.

Furthermore, Rae et al. published an article in Breast Cancer Research and Treatment last year concluded "All currently available stocks of MDA-MB-435 cells are derived from the M14 melanoma cell line and can no longer be considered a model of breast cancer" [6]. They used karyotype, Comparative Genomic Hybridization (CGH), and microsatellite polymorphism analyses, combined with bioinformatics analysis of gene expression and SNP data to test the hypothesis that the MDA-MB-435 cell line is derived from the melanoma cell line M14.

\section{References}

1. Phoenix KN, Vumbaca F, Claffey KP (2008) Therapeutic metfor$\min /$ AMPK activation promotes the angiogenic phenotype in the $\mathrm{ER} \alpha$ negative MDA-MB-435 breast cancer model. Breast Cancer Res Treat. doi:10.1007/s10549-008-9916-5

2. Cailleau R, Olive M, Cruciger QV (1978) Long-term human breast carcinoma cell lines of metastatic origin: preliminary characterization. In Vitro 14(11):911-915

3. Brinkley BR, Beall PT, Wible LJ et al (1980) Variations in cell form and cytoskeleton in human breast carcinoma cells in vitro. Cancer Res 40(9):3118-3129

4. Ross DT, Scherf U, Eisen MB et al (2000) Systematic variation in gene expression patterns in human cancer cell lines. Nat Genet 24(3):227-233

5. Ellison G, Klinowska T, Westwood RF et al (2002) Further evidence to support the melanocytic origin of MDA-MB-435. Mol Pathol 55(5):294-299

6. Rae J, Chad C, Jeanne M et al (2007) MDA-MB-435 cells are derived from M14 Melanoma cells-a loss for breast cancer, but a boon for melanoma research. Breast Cancer Res Treat 104(1):1319

S. M. Hadad $(\bowtie) \cdot$ V. Appleyard · A. M. Thompson Department of Surgery and Molecular Oncology, Ninewells Hospital and Medical School, University of Dundee, Dundee DD1 9SY, UK

e-mail: s.hadad@dundee.ac.uk 